\title{
NOTAS DE JURISPRUDENCIA DEL TRIBUNAL EUROPEO DE DERECHOS HUMANOS
}

\author{
OMAR BOUAZZA ARIÑO' \\ Universidad Complutense de Madrid \\ obouazza@der.ucm.es
}

Cómo citar/Citation

Bovazza Ariño, O. (2017).

Notas de jurisprudencia del Tribunal Europeo de Derechos Humanos.

Revista de Administración Pública, 202, 283-301.

doi: https://doi.org/10.18042/cepc/rap.202.10

\section{SUMARIO}

I. RECURSO DE CASACIÓN: 1. Requisitos de admisión en la casación, eficiencia y derecho a una buena administración de la justicia. 2. Inadmisión y cuantía: formalidades enervantes. Las partes del proceso no deberán cargar con los errores judiciales. 3. El recurso de casación como instrumento de control de convencionalidad en la vía interna. II. DERECHO A LA VIDA: RESPONSABILIDAD DE LA ADMINISTRACIÓN POR OMISIÓN. III. DERECHO AL RESPETO DE LA VIDA PRIVADA Y FAMILIAR: VIDA PRIVADA, RELIGIÓN Y ENSEÑANZA. IV. LIBERTAD RELIGIOSA, ENSEÑANZA Y VESTIMENTA. V. LIBERTAD DE ASOCIACIÓN: DISOLUCIÓN DE ASOCIACIONES DE AFICIONADOS VIOLENTOS DE EQUIPOS DE FÚTBOL. VI. DERECHO AL RESPETO DE LOS BIENES: RESPONSABILIDAD DE LA ADMINISTRACIÓN POR LOS DAÑOS CAUSADOS POR UNA OBRA PÚBLICA EN UN EDIFICIO ILEGAL. VII. INMIGRACIÓN: CONDICIONES DE DETENCIÓN DE EXTRANJEROS IRREGULARES Y EXPULSIONES COLECTIVAS. VIII. SALUD: 1. Vientre de alquiler y derecho al respeto de la vida privada y familiar. 2. Responsabilidad por deficiencias estructurales de los hospitales públicos.

1 Profesor titular de Derecho Administrativo. Este trabajo ha sido realizado en el marco del proyecto de investigación «El reto de la reafirmación del Estado del Bienestar en la protección de los derechos humanos» (DER2015-65524-R), financiado por el Ministerio de Economía y Competitividad (MINECO) y el Fondo Europeo de Desarrollo Regional (FEDER, UE). 


\section{RECURSO DE CASACIÓN}

La jurisdicción contencioso-administrativa constituye una indudable garantía e instrumento, a disposición del administrado, de control del poder. En concreto, de las administraciones públicas. Se trata de un cimiento fundamental para la solidez del Estado de derecho en nuestra sociedad democrática. Una vez consolidado este importante instrumento, habrá que procurar su buen funcionamiento, para la garantía, precisamente, de los administrados que no han obtenido una resolución satisfactoria ante la Administración en la defensa de sus derechos. Por ello, cada vez es más frecuente en los Estados del Consejo de Europa el establecimiento de herramientas, cautelas o requisitos de acceso a la jurisdicción para asegurar que las demandas son serias y así rechazar de antemano aquellas que no alcanzan tales condiciones. En España, parece que la regulación del recurso de casación está depurando y clarificando los requisitos de admisión en cuanto a su preparación e interposición, lo que, unido a la reducción de los asuntos a aquellos que presenten interés casacional, se pretende una reducción del número de asuntos y atender los verdaderamente importantes para la evolución de la jurisprudencia y ofrecer mejores respuestas a los problemas nuevos que se plantean, mejorando el carácter previsible, al haber incorporado en la ley los requisitos que progresivamente fue ańadiendo el Tribunal Supremo, a modo de defensa, ante el atasco de la Sala $3^{\text {a }}$.

\section{REQUISITOS DE ADMISIÓN EN LA CASACIÓN, EFICIENCIA Y DERECHO A UNA BUENA ADMINISTRACIÓN DE LA JUSTICIA}

En Grecia, la regulación de lo contencioso-administrativo igualmente contempla una serie de exigencias que los demandantes deben acatar al presentar su recurso de casación ante el Consejo de Estado. Así, se reserva al Alto Tribunal a los asuntos nuevos e importantes, relativos a preceptos sobre los que no se ha pronunciado previamente, útiles para la sociedad con el objetivo de garantizar también la seriedad de las demandas. Valgan estas notas para introducir la sentencia recaída en el caso Papaioannou c. Grecia, de 2 de junio de 2016.

El demandante, el Sr. Léonidas Papaioannou, es un ciudadano griego que vive en Tesalónica. En octubre de 2008 solicitó a la administración urbanística la declaración de arbitrariedad respecto a ciertas partes de un centro comercial que fue construido cerca de su propiedad. También pedía su demolición. Se queja, entre otras cosas, de que el plan se modificó de una manera ilegal, incorporando una planta más. Como la administración rechazó su solicitud, el demandante recurrió. El Tribunal Administrativo de Apelación observó que la decisión de la administración urbanística contenía un razonamiento suficiente 
y desestimó. Entonces el demandante recurrió en casación ante el Tribunal Supremo Administrativo, refiriéndose en su escrito al artículo 12 de la Ley 3900/2010 y observó que no había precedente de ese tribunal que tratara la cuestión. Además, alegó que el artículo 12 infringía un principio constitucional porque elevaba la jurisprudencia al rango de fuente del derecho. El Tribunal Supremo Administrativo (en adelante, TS) desestimó su recurso en base a que las condiciones de admisibilidad contempladas en el referido precepto no se habían cumplido.

Agotada la vía interna, el demandante acude ante el Tribunal Europeo de Derechos Humanos (en adelante, el Tribunal, Estrasburgo o el TEDH). Alega una violación del artículo 6.1 del Convenio Europeo de Derechos Humanos (en adelante, el Convenio o el CEDH). Se queja de la inadmisión de su recurso por parte del Tribunal Supremo Administrativo, en base al art. 12 de la Ley citada. A su modo de ver, no se ha respetado su derecho de acceso a un tribunal.

El TEDH observa que la finalidad de la Ley 3900/2010 es la de permitir al TS una rápida decisión en casos de interés general y una rápida creación de jurisprudencia que pueda ser seguida por tribunales administrativos inferiores en casos similares. El artículo 12 de la Ley ha sido concebido para limitar la reserva de casos ante el TS y los retrasos significativos en la Administración de justicia. No hay duda de que se trata de fines legítimos para conseguir el objetivo de permitir un trabajo más eficiente de dicho tribunal ${ }^{2}$.

El artículo 12 de la Ley en cuestión dispone que la admisión de un recurso ante el Tribunal Supremo Administrativo exige que el demandante indique y fundamente en su demanda que no hay jurisprudencia en relación con la cuestión legal en entredicho; o que cada uno de los extremos del recurso necesitan una cuestión legal específica decisiva para la resolución de la disputa; y que el aspecto legal de la resolución contradice una jurisprudencia consolidada del Tribunal Supremo Administrativo, de otro tribunal o de tribunales administrativos inferiores. A este respecto, el TEDH considera que el artículo 12 ya había sido el objeto de un cuerpo significativo de jurisprudencia del Tribunal Supremo Administrativo, que clarificó el significado de dicha previsión. En consecuencia, el TEDH considera que las formalidades para la interposición del recurso ante el TS administrativo eran claras, previsibles y perseguían el fin legítimo de asegurar el principio de certeza legal.

2 A este respecto, me remitiré en nuestro país al trabajo de Germán Fernández Farreres (2015), «Sobre la eficiencia de la jurisdicción contencioso-administrativa y el nuevo recurso de casación "para la formación de jurisprudencia"”, Revista Española de Derecho Administrativo, 174, págs. 93-132. 
En este caso, el demandante explicó en su recurso que no había jurisprudencia del TS en torno a dicha cuestión. Además, dijo que el art. 12 era inconstitucional, a la luz del art. 26 de la Carta Magna, porque elevaba el rango de la jurisprudencia a fuente del derecho. Su recurso fue inadmitido por el Tribunal Supremo administrativo, que consideró que las condiciones de admisibilidad contempladas en el artículo 12 no se cumplieron y que la cuestión de la conformidad del artículo 12 con la Constitución ya se había resuelto. En efecto, el TEDH observa que el Tribunal Supremo Administrativo ya se ha pronunciado sobre la cuestión de la constitucionalidad de dicho precepto el 5 de julio de 2012 (sentencia del TS administrativo 2456/2012) y que el recurso del demandante se presentó el 1 de octubre de 2012. Además considera que el argumento del demandante sobre la ausencia de jurisprudencia se formuló de una manera lacónica sin dar una explicación clara sobre qué cuestión de naturaleza legal no se había cubierto por la jurisprudencia establecida sobre dicho precepto.

Teniendo en cuenta el papel específico del TS administrativo en asegurar la consistencia de la jurisprudencia, el TEDH adopta el punto de vista de que la imposición de condiciones de admisibilidad para procedimientos ante el Tribunal podría aceptarse. Es más, considera que sujetar la admisión de un recurso a la existencia de circunstancias objetivas que deben ser demostradas por el demandante, tal y como establece la ley y es interpretado por los tribunales administrativos, no es por sí mismo desproporcionado ni viola el derecho de acceso al TS administrativo. El TEDH observa, por consiguiente, que el demandante no ha sido privado de su derecho de acceso a un tribunal, que las limitaciones en cuestión perseguían un fin legítimo y que se había mantenido una relación razonable de proporcionalidad entre los medios empleados y la finalidad a alcanzar.

Por todo ello, el TEDH concluye que el demandante no ha sufrido una limitación desproporcionada en su derecho de acceso a un tribunal y que no ha habido una violación del artículo 6.1 CEDH.

\section{INADMISIÓN Y CUANTÍA: FORMALIDADES ENERVANTES. LAS PARTES DEL PROCESO NO DEBERÁN CARGAR CON LOS ERRORES JUDICIALES}

En la sentencia recaída en el caso Zubac c. Croacia, de 11 de octubre de 2016, se denegó a la demandante el acceso a la casación en el ámbito del TS croata en una demanda sobre propiedad. El TS inadmitió porque la cuantía de la demanda era inferior al mínimo de las 100000 kunas croatas exigidas por la Ley. El TEDH observa que si bien la cuantía inicialmente se fijó en las 10000 kunas, la demandante, ante el tribunal de primera instancia, planteó una cuantía de 105000 kunas, que sería aceptada por el órgano judicial tras 
su valoración. Y así, tanto el tribunal en primera como en segunda instancia mantuvo la nueva cuantía en sus sentencias. $Y$ en este sentido, la demandante tuvo que pagar las costas y gastos del proceso de conformidad con la nueva cuantía.

El TEDH reconoce que dada la especial naturaleza del papel de los tribunales de casación, que se limita a la revisión de si el derecho ha sido correctamente aplicado, el TEDH acepta que el procedimiento seguido en estos tribunales puede ser más formal, como indicó, por ejemplo, en la sentencia recaída en el caso Meftah y otros c. Francia, de 26 de julio de 2002. El «derecho a un tribunal», continúa, del que el derecho de acceso es un aspecto, no es absoluto. Está sujeto a limitaciones en cuanto a que los Estados gozan de margen de discreción en el establecimiento de condiciones de admisión. No hay, sin embargo, una libertad absoluta, en el bien entendido de que dichas limitaciones no deben impedir o restringir el derecho de acceso de tal manera que afecte a la esencia de los derechos reconocidos en el artículo $6 \mathrm{CEDH}$. En concreto, dichas limitaciones solo serán compatibles con el artículo $6.1 \mathrm{si}$ persiguen un fin legítimo y hay proporcionalidad entre los medios empleados y el fin legítimo perseguido, como se dijo, por ejemplo, en la sentencia recaída en el caso Guérin c. Francia, de 29 de julio de 1998.

El TEDH observa que corresponde en primer lugar a los tribunales internos la interpretación del derecho nacional. El papel del Tribunal está limitado a verificar la compatibilidad de los efectos de tales interpretaciones con el Convenio. Esto es aplicable en concreto a la interpretación por los tribunales de las reglas de naturaleza procesal, como dijo en la sentencia recaída en el caso Tejedor García c. España, de 16 de diciembre de 1997. El TEDH hará su evaluación en cada caso a la luz de las características especiales del procedimiento en cuestión y en relación con la finalidad del artículo 6.1. El TEDH a continuación dirá que incluso asumiendo que hubo un error de cálculo en el ámbito de los tribunales inferiores al permitir a la demandante el cambio del valor del objeto de la disputa en un avanzado estado del procedimiento, bien que no se reunían los requisitos procesales para tal acción, considera que la demandante actuó correctamente al recurrir y esperar la decisión sobre el fondo del TS. En esta línea, el TEDH dirá que el riesgo derivado de cualquier error cometido por una autoridad del Estado debe ser asumido por el Estado y los errores no deben ser remediados a costa del ciudadano afectado, como ha dicho en varias sentencias, como en las recaídas en los casos Platakou $c$. Grecia, de 11 de enero de 2001, Freitag c. Alemania, de 19 de julio de 2007 y Šimecki c. Croacia, de 30 de abril de 2014. En efecto, el TEDH ha dicho en estas sentencias que las partes del proceso no deben cargar con las consecuencias negativas de los errores cometidos por los tribunales. Al hacer cargar a la demandante con las consecuencias del error judicial, se ha violado el principio 
general de equidad procesal inherente al artículo 6.1 del Convenio, impidiendo su derecho de acceso a un tribunal. En consecuencia, el TEDH concluye que ha habido una violación del artículo 6.1 CEDH.

\section{EL RECURSO DE CASACIÓN COMO INSTRUMENTO DE CONTROL DE CONVENCIONALIDAD EN LA VÍA INTERNA}

En la Decisión de Inadmisión Abramyan y Yakubovskiye c. Rusia, de 12 de mayo de 2015, el TEDH observa que el procedimiento del nuevo recurso de casación instaurado en Rusia, mediante la Ley 353-FZ, constituye un recurso efectivo, por lo que se deberá emplear para que se produzca el agotamiento de la vía interna. Veamos con más detenimiento los hechos, la argumentación del Tribunal y la Decisión.

Los demandantes son miembros de una cooperativa de usuarios de barcos. Un Ayuntamiento les demandó por adquirir ilegalmente un suelo en el que construyeron cobertizos. El tribunal de primera instancia resolvió en contra de los demandantes, pero la sentencia fue anulada en apelación. Aunque la sentencia que se dictó a favor de los demandantes era vinculante, el ayuntamiento, en base a la legislación interna, podía interponer un recurso de casación ante la Sala Principal del tribunal regional. Los demandantes perdieron el caso ante la primera instancia del tribunal regional en 2013 y sus cobertizos fueron derribados poco después. En sus demandas ante el TEDH, los demandantes consideran que la sentencia dictada a su favor era firme, por lo que la sentencia dictada en casación habría violado a su modo de ver el principio de certeza legal y sus derechos en base al artículo 6.1 CEDH y el artículo 1 del protocolo adicional al Convenio.

El Gobierno argumentó que los recursos de los demandantes debían ser inadmitidos ya que se habían interpuesto fuera del plazo de los seis meses y porque no habían agotado la vía interna. Al considerar la admisión de la demanda de los recurrentes, el TEDH tiene la posibilidad de examinar por primera vez un nuevo proceso en casación que ha sido introducido en el ordenamiento interno en 2012.

\subsection{Sobre si el procedimiento de revisión ante la Sala Principal del Tribunal Supremo constituye un recurso que debe ser agotado}

En relación con la alegación del Gobierno de que los demandantes no han interpuesto una demanda de revisión ante la Sala Principal del TS, el TEDH observa que tal demanda de revisión solo puede ser interpuesta por una parte cuyo recurso de casación ha sido previamente examinado sobre el fondo por la Sala Civil del TS. Sin embargo, en las circunstancias del caso de 
los demandantes, en las que tal examen no ha tenido lugar, la demanda de revisión no ha podido ser interpuesta. El argumento del Gobierno de que los demandantes no han agotado la vía interna por consiguiente se inadmite.

\subsection{Sobre si el nuevo procedimiento introducido por la Ley 353-FZ implica un recurso que requiere agotamiento y fue relevante para el cálculo del plazo de seis meses}

Los demandantes han interpuesto sus demandas después de los seis meses de la desestimación del recurso de casación por un juez único del TS y menos de seis meses después de que la decisión de desestimación fuera confirmada por el presidente del TS. El TEDH debe determinar por tanto en qué fecha fue adoptada la decisión final en el caso para la determinación de si se ha respetado el plazo de los seis meses.

En su jurisprudencia referida a Rusia, el TEDH ha sostenido que una decisión adoptada por un tribunal de segunda instancia a nivel regional en base a la anterior regulación de la casación era una decisión firme a los efectos del art. 35 del Convenio y el punto de partida para el cálculo del plazo de seis meses. Las demandas de revisión a tribunales superiores — las salas de gobierno de tribunales regionales, la sala civil del TS y la sala de gobierno de este último y las decisiones adoptadas por ellos en revisión de sentencias - no han sido consideradas relevantes a los efectos del cálculo del plazo. Sin embargo, el recurso de casación en el caso que aquí se examina ha sido ejercido en base a un nuevo procedimiento introducido en 2012. Con la finalidad de establecer si las quejas de los demandantes se han interpuesto en plazo, el Tribunal tiene que evaluar si el nuevo procedimiento implica un remedio que requiera el agotamiento de la vía interna por los demandantes en base al art. 35.1, relevante para el cálculo del plazo de seis meses. Es decir, se deberá analizar si acudir al nuevo recurso de casación es un requisito para entender agotada la vía interna, a diferencia de lo que ocurría antes de su entrada en vigor.

El TEDH examina varios aspectos del nuevo procedimiento de casación y observa que no se puede seguir considerando como un recurso extraordinario. En concreto, la reforma limita el procedimiento de casación solo a dos niveles de jurisdicción y prevé plazos específicos para cada fase en el examen del caso, eliminando así la incerteza que causaba el sistema de revisión previo. Es más, el nuevo procedimiento de casación permite a las partes someter ante las autoridades internas, incluso el TS, el conocimiento sobre si se ha producido una violación del Convenio y obtener, en su caso, reparación, con lo que funcionaría como un recurso genuino en la tutela de derechos e intereses de control de la convencionalidad de la actuación de las autoridades internas. El nuevo procedimiento debe considerarse, por tanto, como un recurso ordina- 
rio que conoce sobre el fondo sobre cuestiones de derecho. Por consiguiente, estaba justificado requerir a las personas que tuvieran la intención de interponer una demanda sobre una alegada violación de los derechos del Convenio la utilización, en primer lugar, de las dos vías de casación en base al nuevo procedimiento. En línea con el principio de subsidiariedad, el reconocimiento del procedimiento de casación como un recurso a agotar permite a los demandantes, según la nueva regulación, someter previamente sus reclamaciones ante el máximo órgano judicial, que puede tener una oportunidad adecuada en la consideración de una demanda sobre una violación alegada del Convenio en casos civiles y remediar cualquier violación antes de su examen por el TEDH. Sin embargo, el funcionamiento efectivo del sistema de la casación para la revisión de sentencias vinculantes y ejecutivas dependerá del cumplimiento estricto de los plazos establecidos en el derecho interno y en el efectivo acceso al TS, que debe estar disponible no solo en teoría sino también en la práctica. En relación con la queja de los demandantes al presidente del TS, en cuanto era un recurso que dependía de un poder discrecional de un oficial y no estaba sujeto a un plazo, debía considerarse un recurso extraordinario que los demandantes no tenían la obligación de agotar. En cualquier caso, la decisión final a nivel nacional en el caso de los demandantes ha sido la decisión del juez del TS, que ha sido dictada más de seis meses antes de que los demandantes hayan interpuesto sus demandas ante el TEDH. Las demandas, por tanto, se han interpuesto fuera de plazo, por lo que el TEDH declarará la inadmisión de las demandas (art. $35 \mathrm{CEDH}$ ).

Un caso similar es el conocido en la sentencia Sakhanov c. Rusia, de 18 de octubre de 2016. La reforma de la Constitución introducida por la Ley de la reforma constitucional $n^{\circ}$ 2-FKZ de 6 de febrero de 2014 prevé la abolición del Tribunal Supremo Comercial tras un periodo provisional de seis meses, con la transferencia gradual de todas sus funciones al TS. La modificación del Código de Procedimiento en materia de comercio, que entró en vigor el 6 de agosto de 2014, otorga al TS el conocimiento de la casación y de las apelaciones contra las decisiones definitivas de los tribunales comerciales.

El demandante alega ante el TEDH una violación de los artículos 6 y 13 $\mathrm{CEDH}$ y del artículo 1 del protocolo adicional al Convenio, tras las sentencias desfavorables obtenidas en el ámbito de los tribunales comerciales rusos. No ha interpuesto una demanda para la revisión en casación ante la Cámara del TS en el procedimiento interno. La cuestión a esclarecer será entonces si se ha producido el agotamiento de la vía interna.

El procedimiento en casación introducido para los tribunales comerciales rusos por la nueva legislación es muy similar al de la casación y al procedimiento de revisión establecido para la jurisdicción general. En concreto, la segunda vía de casación ante el TS permite a los demandantes potenciales 
someter sus demandas ante el más alto órgano judicial de la Federación de Rusia, apta para conocer de cualquier alegación de violación del Convenio en casos sobre comercio y ofrecer una respuesta a violaciones de derechos en el nivel interno previamente al examen del TEDH.

El TEDH, por consiguiente, considera apropiado basarse en las conclusiones a las que llegó en el caso anterior comentado, Abramyan y Yakubovskiye c. Rusia referido a la eficacia de los recursos de casación así como la supervisión en casos civiles ante el TS. Así, una demanda de casación ante la Cámara del TS, basada en plazos estrictos, constituye un recurso efectivo apto para resarcir y requerir el agotamiento en disputas sobre temas de comercio. Como el demandante no ha interpuesto el recurso ante la Cámara del TS, no ha agotado la vía interna, por lo que el TEDH declara la inadmisibilidad de la demanda.

\section{DERECHO A LA VIDA: RESPONSABILIDAD DE LA ADMINISTRACIÓN POR OMISIÓN}

En la sentencia recaída en el caso Cevrioğlu c. Turquía, de 4 de octubre de 2016, el hijo del demandante y un amigo murieron ahogados al caer en un gran agujero lleno de agua en una construcción privada de una zona residencial. Poco después del accidente, se inició un proceso penal contra el propietario de la construcción y tres empleados municipales. Uno de los tres informes de expertos que se ofrecieron en este caso indicó que la responsabilidad por los hechos había que imputarla al Ayuntamiento y al propietario del sitio y no a los menores. El tribunal penal decidió que el propietario del sitio y el director de reconstrucción del ayuntamiento fueron culpables por causar la muerte por negligencia y no cumplir la normativa. Sin embargo, esta sentencia sería recurrida y la visión unánime de los tribunales en la vía interna sería la de la exención de responsabilidad del ayuntamiento, contemplando únicamente la culpabilidad de la empresa privada. A fecha de interposición del recurso ante el TEDH, el demandante no había recibido indemnización alguna. Ante el TEDH alegó que las autoridades del Estado fallaron en la protección del derecho a la vida de su hijo.

El TEDH comienza su argumentación indicando que la obligación del Estado en base al artículo 2 en casos sobre infracción no intencionada del derecho a la vida no se limita a la adopción de normativas para la protección de la seguridad de los ciudadanos en lugares públicos sino que también incluye un deber de asegurar el funcionamiento efectivo del marco normativo.

En ausencia de las necesarias precauciones de seguridad, los sitios en construcción, especialmente en zonas residenciales, son peligrosos no solo para los trabajadores, que están más familiarizados con los posibles riesgos, sino también para los ciudadanos en general, incluyendo los grupos más vulnerables, como 
los menores, que pueden ser fácilmente objeto de esos riesgos. Es por ello que el Tribunal considera que si bien hay casos en los que la inexistencia de un riguroso procedimiento de inspección no supone problema alguno, los Estados tienen, en casos como el presente, una mayor responsabilidad hacia los ciudadanos en general, que tienen que vivir con los peligros reales que supone una obra en su vecindad. Si bien el TEDH reconoce que la responsabilidad principal es del propietario de la obra, el hecho de que el Estado no haya planteado un sistema efectivo de inspección puede observarse como un factor relevante.

Aunque el Gobierno ha argumentado que el accidente no era previsible ya que la obra había comenzado recientemente, el TEDH constata que en realidad el agujero estaba hecho desde hacía al menos dos meses, por lo que el Estado debió realizar la correspondiente inspección. Si bien no puede especular si la correspondiente inspección hubiera evitado el accidente, tal inspección hubiera forzado al propietario a cerrar el sitio y tomar precauciones en relación con el agujero, lo cual desde una perspectiva objetiva hubiera exonerado la responsabilidad del Estado en relación con el artículo $2 \mathrm{CEDH}$. Por todo ello, el TEDH concluye por unanimidad que ha habido una violación del artículo 2 del Convenio.

\section{DERECHO AL RESPETO DE LA VIDA PRIVADA Y FAMILIAR: VIDA PRIVADA, RELIGIÓN Y ENSEÑANZA}

En la sentencia recaída en el caso Travaš c. Croacia, de 4 de octubre de 2016, el demandante estaba empleado por el Estado para enseñar la asignatura de Religión Católica en las escuelas. Tras su divorcio, contrae matrimonio civil. La Iglesia entonces revocó su mandato religioso y fue despedido. En su demanda ante el TEDH, el demandante se queja de que su despido ha constituido una interferencia injustificada en el ejercicio de su derecho a su vida privada y familiar.

El TEDH sostiene que el despido del demandante ha implicado una interferencia en su vida privada. La interferencia estaba prevista en la Ley y perseguía el fin legítimo de la protección de los derechos y libertades de la Iglesia católica. Analizará si la medida debe considerarse necesaria en una sociedad democrática, de conformidad con los criterios establecidos en el asunto Fernández Martínez c. España, de 15 de mayo de 2012: la exposición de su situación, la responsabilidad del Estado como empleador, la severidad de la sanción y la revisión por los tribunales internos ${ }^{3}$.

3 Comenté la sentencia referida a España en el número 189 (2012), pág. 322, de esta revista. También debe citarse en esta línea la sentencia Lombardi Vallauri c. Italia, de 20 
El TEDH observa que el demandante era un maestro laico de Religión Católica, empleado por el Estado. Un acuerdo entre la Santa Sede y Croacia en asuntos religiosos y culturales hizo necesario ostentar un mandato canónico para enseñar esta asignatura. En el procedimiento interno reconoció que sabía las consecuencias de su conducta en su mandato como profesor por la Iglesia católica. Al aceptar el trabajo sabía de la importancia del sacramento del matrimonio para la Iglesia. Sus propios actos le llevaron a perder el mandato canónico. El hecho de que no se haya dado publicidad a su estilo de vida y conducta, vista por la Iglesia como contraria a los preceptos de su doctrina, no fue un elemento decisivo en la evaluación de las consecuencias de la decisión del despido del demandante. El TEDH da especial importancia al hecho de que el demandante no haya sido despedido directamente tras la retirada del mandato canónico por la Iglesia. Las escuelas terminaron su contrato de empleo tras examinar la posibilidad de encontrarle otro puesto adecuado. El demandante ha tenido derecho a indemnización y ha podido solicitar la prestación por desempleo. El TEDH observa que esto representó un esfuerzo especial por el Estado al encontrar un equilibrio en la protección de su vida privada y profesional y el ejercicio de la autonomía de la Iglesia. No había duda de que el despido constituyó una sanción que conllevó serias consecuencias. Sin embargo, el despido no se debió de una manera directa e incondicional a la retirada de su mandato canónico sino a la imposibilidad objetiva de encontrar otro puesto adecuado para él. El demandante tenía libertad para buscar otro empleo en el sistema educativo enseñando ética y cultura. Además, el demandante ha tenido acceso a la justica para denunciar la situación, tanto en la vía ordinaria como en el ámbito constitucional. El TC examinó detalladamente el acuerdo especial entre el Estado y la Iglesia católica en materia de la enseńanza de la religión católica en el sistema de enseńanza. Examinó también la razonabilidad del requisito de tener un mandato canónico para enseñar religión católica y su proximidad a la misión de diseminar las enseñanzas de la Iglesia. El TEDH observa que las autoridades internas han realizado una justa ponderación de los intereses en conflicto y sus conclusiones no parecen irrazonables. El Tribunal concluye que, teniendo en cuenta el margen de apreciación del Estado, la interferencia en el derecho del demandante al respeto de su vida privada y familiar no ha sido desproporcionada.

de octubre de 2009. El profesor Lorenzo Martín-Retortillo (2010) ha estudiado esta sentencia en su trabajo «Selección de profesores en Universidad Católica y respeto del ideario: (Sentencia del Tribunal Europeo de Derechos Humanos, "Lombardi Vallauri c. Italia”, de 20 de octubre de 2009)», Revista Española de Derecho Administrativo 147, págs. 649-668. 
Por todo ello, concluye, por unanimidad, que no ha habido una violación del artículo $8 \mathrm{CEDH}$.

\section{LIBERTAD RELIGIOSA, ENSEÑANZA Y VESTIMENTA}

En la sentencia recaída en el caso Osmanoğlu y Kocabaşc. Suiza, de 10 de enero de 2017, los demandantes pretendían que sus hijas, que no han alcanzado la pubertad, no acudieran a las clases obligatorias de natación del colegio. Las autoridades no accedieron ante dichas pretensiones. El TEDH considera que el derecho a manifestar la religión estaba en juego en este caso y que la denegación de las autoridades nacionales de la exención en la asistencia de las clases obligatorias de natación constituía una interferencia en el derecho de religión, contemplada en la ley y que perseguía un fin legítimo: la protección de los alumnos extranjeros de cualquier forma de exclusión social.

El TEDH enfatiza, sin embargo, que la escuela juega un papel esencial en el proceso de integración social, particularmente para los niños de origen extranjero. Observa que el interés de las niñas en una educación total, facilitando su integración social exitosa de acuerdo con las costumbres locales y morales, tiene preferencia frente al deseo de los padres de que sus hijas queden exentas de lecciones mixtas de natación. El interés de las niñas de asistir a las lecciones de natación no solo radica en el aprendizaje de la natación, continúa el TEDH, sino en la participación en una actividad con todos los demás alumnos sin excepción por el origen de los padres o sus convicciones religiosas y filosóficas. El TEDH también observa que las autoridades han ofrecido a los demandantes acuerdos muy flexibles para reducir el impacto de la asistencia de las niñas a las clases mixtas de natación en las convicciones religiosas de los padres. Las autoridades académicas permitieron a sus hijas asistir a dichas clases en burkini, una prenda de baño que cubre la totalidad del cuerpo excepto el rostro, manos y pies. Observa también que el procedimiento en este caso ha sido accesible y el caso ha sido conocido en el ámbito interno sobre el fondo. El TEDH, por tanto, dando preferencia a la obligación de las niñas de asistir a la totalidad de las clases del currículum escolar y su integración exitosa frente al interés privado de los demandantes de eximir a las niñas de la asistencia a clases de natación por razones religiosas, las autoridades internas, dice el TEDH, no se han excedido del margen de apreciación del que gozan en materia de enseñanza obligatoria. Por ello, no ha habido una violación del art. $9 \mathrm{CEDH}^{4}$.

4 Sobre la religión y la conciencia y la manera de ir vestido en público, véase el interesante trabajo de Lorenzo Martín-Retortillo (2015), «El debate sobre el uso de los 


\section{LIBERTAD DE ASOCIACIÓN: DISOLUCIÓN DE ASOCIACIONES DE AFICIONADOS VIOLENTOS DE EQUIPOS DE FÚTBOL}

En la sentencia recaída en el caso «LES AUTHENTIKS» y «SUPRAS AUTEUIL 91» c. Francia, de 27 de octubre de 2016, las demandantes son dos asociaciones de aficionados del equipo de fútbol francés Paris St. Germain. El 28 de febrero de 2010, en el encuentro deportivo entre los equipos Paris St. Germain y el Olympique de Marsella, se produjo una pelea entre los miembros de las asociaciones mencionadas y miembros de otra asociación ya disuelta, los Boulogne Boys. La pelea se saldó con un aficionado muerto.

La comisión nacional de prevención de la violencia informó a las dos asociaciones la intención del Gobierno de proceder a su disolución indicándoles los cargos que se les imputaban. Tras abrir una fase de audiencia a las interesadas, la comisión dictó un informe favorable a su disolución. El primer ministro firmaría dos decretos pronunciando la disolución de las dos asociaciones fundándose en los actos repetidos de degradación de bienes y de violencia sobre las personas, cometidas en conjunto por sus miembros, teniendo en cuenta, entre otros, los hechos del 28 de febrero de 2010.

El 7 de mayo de 2010 las asociaciones solicitaron al Consejo de Estado la suspensión de la ejecución de los decretos. El mismo día interpusieron ante el Consejo de Estado una solicitud de anulación. Por dos autos de 7 de junio de 2010, el juez del Consejo de Estado rechazó las solicitudes de suspensión de las medidas de disolución. El mismo órgano judicial rechazó los recursos por exceso de poder interpuestos por las asociaciones el 13 de julio de 2010, basándose en los hechos del 28 de febrero de 2010, sin atender a los motivos de la disolución, que integran los hechos del 28 de febrero de 2010 y otras circunstancias. Juzgó las medidas de disolución proporcionadas a la vista de los riesgos para el orden público que presentan las acciones de algunos de los integrantes de las asociaciones.

En base al artículo $8 \mathrm{CEDH}$ las asociaciones demandantes alegan que las sustituciones de motivos realizadas por el juez para validar las disoluciones han violado el principio de contradicción del procedimiento. Se quejan igualmente de la imposibilidad de presentar observaciones orales ante el Consejo de Estado. Alegan en fin que su disolución constituye una injerencia desproporcionada en su derecho garantizado en el artículo 11 (libertad de reunión y de asociación).

espacios públicos, ¿andar desnudo por la calle o con la cara tapada?», Asamblea: Revista Parlamentaria de la Asamblea de Madrid, 33, págs. 13-72. 
En relación con la alegación del principio contradictorio, el TEDH observa que el Consejo de Estado ha tenido en cuenta los hechos y no ha tenido en cuenta los motivos que justificaron los decretos de disolución. No obstante, las partes han tenido oportunidad de debatir tanto los hechos del 28 de febrero de 2010 como la sustitución de los motivos. El Tribunal estima por ello que dicha sustitución no ha afectado al derecho de las asociaciones a un proceso equitativo.

En relación con la alegación de la imposibilidad de presentar observaciones orales ante el Consejo de Estado, la especificidad del procedimiento ante un tribunal supremo puede justificar la reserva a los abogados especializados del monopolio de la toma de la palabra. El Tribunal considera que la alegación está manifiestamente mal fundada.

En relación con el artículo 11, el TEDH constata que ambas partes aceptan que la medida ha supuesto una interferencia en la libertad de asociación de las demandantes, recogida en el art. $11 \mathrm{CEDH}$. El TEDH observa que el Consejo de Estado ha considerado que los hechos del 28 de febrero de 2010, que tuvieron como consecuencia la muerte de un aficionado, justifican la disolución de las dos asociaciones. En efecto, algunos de sus miembros han sido identificados de entre los participantes en la pelea en cuestión.

En relación con el contexto en el que se han adoptado las medidas litigiosas, el TEDH admite que las autoridades nacionales han podido considerar que existía una necesidad social imperiosa de imponer restricciones drásticas en relación con los grupos de aficionados, como lo son en este caso las medidas litigiosas. Las medidas de disolución fueron por tanto necesarias en una sociedad democrática, en la defensa del orden y de la prevención del delito.

El Tribunal subraya que las asociaciones cuyo fin oficial es la promoción de un club de fútbol no tienen la misma importancia para una democracia que un partido político. Además, admite que el margen de apreciación en materia de incitación al uso de la violencia es particularmente amplio. A este respecto, y en consideración al contexto, el TEDH concluye que las medidas de disolución pueden considerarse proporcionadas al fin legítimo perseguido. No ha habido, por tanto, una violación del artículo $11 \mathrm{CEDH}$.

\section{DERECHO AL RESPETO DE LOS BIENES: RESPONSABILIDAD DE LA ADMINISTRACIÓN POR LOS DAÑOS CAUSADOS POR UNA OBRA PÚBLICA EN UN EDIFICIO ILEGAL}

En la sentencia recaída en el caso Keriman Tekin y otros c. Turquía, de 15 de noviembre de 2016, los demandantes son propietarios de un solar en un terreno inestable. Construyeron una casa en 1997, sin pedir permiso de obra. 
En 2004, las obras de construcción de una escuela en una parcela vecina provocaron un corrimiento de tierra que dañó la casa de los demandantes hasta el punto de hacerla inhabitable.

Los demandantes plantearon una acción de indemnización contra la administración responsable de las obras. Varios expertos informaron que las carencias que presentaba la construcción de los demandantes contribuyeron en un 15 a $20 \%$ en los daños sufridos. Los tribunales rechazaron cualquier pretensión de indemnización, ni total ni parcial, por los siguientes motivos: no intentaron en ningún momento regularizar su construcción, la situación de su bien no era regularizable por razones urbanísticas así como por las características de las técnicas de la construcción.

El TEDH comienza su argumentación constatando que la casa de los demandantes fue erigida en un terreno que les pertenecía sin obtener el permiso de obra, en violación del derecho urbanístico. Tampoco disponían del permiso de habitabilidad, lo que en España denominaríamos la cédula de habitabilidad.

Sin embargo, los demandantes nunca fueron intimados por la Administración por la situación de ilegalidad del bien. Nada indica que las autoridades tuvieran intención de hacer uso de sus potestades legales de exigirles la demolición de la construcción en causa. Además, la afirmación de los demandantes de que ninguna construcción de la zona administrativa concernida goza de permiso de obra no ha sido rebatida por las autoridades internas. En fin, la casa está inscrita en el registro de la propiedad sin anotación especial. Consta como una propiedad de los demandantes.

A la vista de estos elementos, el TEDH observa que los demandantes disponen de un interés patrimonial a gozar de su casa, interés suficientemente reconocido e importante para considerarlo un bien. Por ello, el TEDH considera que es aplicable el artículo 1 del protocolo adicional al Convenio. Los dańos ocasionados se refieren por consiguiente a la imposibilidad de hacer uso de su casa.

La casa de los demandantes fue construida en un momento en el que no había plan urbanístico municipal. La construcción fue realizada sin la autorización requerida y el derecho interno permitía a las autoridades ordenar la demolición para sancionar el incumplimiento de la legislación urbanística.

Los daños han sido causados de manera fortuita y las autoridades no han adoptado en ningún momento la decisión de demolición, aspecto que distingue este caso de la decisión Tiryakioğlu c. Turquía, de 13 de mayo de 2008, y de la sentencia Hamer c. Bélgica, de 27 de noviembre de 2007. Al contrario, la cuestión del permiso ha sido tratada por primera vez en el curso del procedimiento relativo a la demanda de indemnización para exigir su responsabilidad. El TEDH observa que no hay nada que demuestre que las autoridades turcas 
hayan llevado a cabo una política coherente de lucha contra las construcciones ilegales ni que hayan decidido, por tanto, derribar las construcciones ilegales. Ni la administración ni el gobierno han contradicho ante el TEDH que casi ninguna construcción de la división administrativa disponga de autorización. La práctica legislativa de las «amnistías urbanísticas» parece testimoniar el amplio fenómeno de construcciones sin autorización en el Estado, de la tolerancia de las autoridades frente a ella y de su voluntad de regularizar la situación jurídica de las obras concernidas.

El motivo alegado para rechazar la indemnización de los demandantes no se refiere a consideraciones vinculadas a la protección del medio ambiente. En estas circunstancias, la denegación de las autoridades de reparar el perjuicio material causado ha hecho pesar sobre los demandantes una carga especial y exorbitante que ha roto el justo equilibrio entre sus intereses y los de la comunidad. Por ello, el TEDH concluye, por unanimidad, que ha habido una violación del derecho al respeto de los bienes de los demandantes (artículo 1 del protocolo adicional al Convenio).

\section{INMIGRACIÓN: CONDICIONES DE DETENCIÓN DE EXTRANJEROS IRREGULARES Y EXPULSIONES COLECTIVAS}

En la sentencia recaída en el caso Khalifia y otros $c$. Italia, de 1 de septiembre de 2015, el TEDH conoció de la detención de migrantes clandestinos en un centro de recepción de la isla de Lampedusa y en barcos amarrados en el puerto de Palermo, así como su repatriación a Túnez. Llegaron a la costa italiana en 2011 durante los acontecimientos vinculados a la "Primavera Árabe».

El TEDH sostuvo que la detención de los demandantes fue ilegal. No se les notificó las razones de la detención — para las que no había base legal—y no pudieron impugnarlas. En relación con las condiciones de su detención en el centro de recepción, el Tribunal tiene en cuenta la excepcional crisis humanitaria que afronta Italia en la isla de Lampedusa, que fue especialmente cruenta en 2011, momento en el que arribaron 55298 migrantes, de entre los que se encontraban los demandantes. El TEDH, no obstante, concluye que las condiciones de la detención de los demandantes afectaron a su dignidad humana, aunque no en el caso de los barcos atracados en el puerto de Palermo.

El Tribunal, además, consideró que los demandantes sufrieron una expulsión colectiva al no tenerse en consideración sus circunstancias personales en el procedimiento de devolución. El TEDH observa, en concreto, que el procedimiento de identificación fue insuficiente. Además, el Tribunal subraya que en aquel momento numerosos tunecinos fueron devueltos en base a procedimientos simplificados. Finalmente, el Tribunal considera que los de- 
mandantes no han dispuesto de un recurso efectivo para plantear una queja porque, en base al artículo $13 \mathrm{CEDH}$, para que un recurso sea efectivo, en un caso de expulsión colectiva, el procedimiento debería quedar automáticamente suspendido, lo que no ocurrió en este caso al ser devueltos a Túnez.

En fin, el TEDH resolvió por unanimidad que hubo una violación del artículo $5 \mathrm{CEDH}$ (derecho a la libertad), no así del artículo 3 (prohibición de tratos inhumanos o degradantes), en cuanto a las condiciones de detención en los barcos amarrados en Palermo. Por mayoría, decidió que hubo una violación del artículo 3, en relación con las condiciones de detención en Lampedusa. Igualmente, por mayoría, reconoció una violación del artículo 4 del protocolo núm. 4, que prohíbe la expulsión colectiva de extranjeros, así como del artículo 13 (derecho a un recurso efectivo) tenido en consideración conjuntamente con los artículos 3 y 4 del protocolo núm. 4.

El Gobierno italiano solicitó, el 1 de diciembre de 2015, el conocimiento de este caso por la Gran Sala, compuesta por 17 jueces. En esta sede reforzada del TEDH se reconocerá esencialmente lo dictaminado por la Sala en la Sentencia de 15 de diciembre de 2016. No obstante, cambia de criterio en cuanto a la prohibición de expulsiones colectivas. Como he indicado antes, la Sala observó una violación de dicha prohibición. Sin embargo, la Gran Sala, por 16 votos a 1, observa que el artículo 4 del Protocolo núm. 4 no garantiza el derecho a una entrevista individual en todo tipo de circunstancias. Las exigencias de dicha previsión fueron satisfechas, ya que todo extranjero tuvo la posibilidad de exponer sus argumentos contra su expulsión y fueron examinadas por las autoridades internas. Los extranjeros fueron identificados en dos ocasiones y su nacionalidad fue determinada, por lo que el TEDH entiende que tuvieron una posibilidad efectiva y genuina de exponer argumentos contra su expulsión.

\section{SALUD}

\section{VIENTRE DE ALQUILER Y DERECHO AL RESPETO DE LA VIDA PRIVADA Y FAMILIAR}

En la sentencia recaída en el caso Paradiso y Campanellic. Italia, de 27 de enero de 2015, los demandantes celebraron en Rusia un acuerdo de gestación subrogada con una mujer del país. A la vuelta, trascendió a las autoridades públicas italianas que habían adquirido el niño de esa manera, no permitida en Italia, con lo que se les retiró el bebé, de 9 meses de edad, y se derivó a un centro de servicios sociales. El TEDH señaló que las autoridades italianas, al adoptar la decisión en base a las políticas públicas del país en materia de gesta- 
ción subrogada y las normas de adopción internacional, puede que no hayan tenido en cuenta el interés superior del menor. Subrayó que separar al niño de los demandantes fue una medida extrema que solo se justifica en el caso de un peligro inmediato. Sin embargo, el TEDH dijo que esto no debe entenderse como una obligación a Italia de devolver el niño a los demandantes, ya que indudablemente el menor habría desarrollado lazos emocionales con la familia adoptiva con la que ha estado viviendo desde 2013. Se concluyó, por cinco votos contra dos, que ha habido una violación del artículo $8 \mathrm{CEDH}$ (derecho al respeto de la vida familiar).

La sentencia fue recurrida por el Gobierno. El TEDH, en Gran Sala, ha cambiado de criterio. En efecto, en esta sala integrada por 17 jueces, ha considerado que teniendo en cuenta la ausencia de lazos biológicos entre el niño y los demandantes, la corta duración de su relación con el niño, la incerteza de los lazos entre ellos desde una perspectiva legal así como de la calidad de los lazos emocionales y de un proyecto familiar, el TEDH sostiene que no puede decirse que haya habido una vida familiar entre los demandantes y el niño. Considera, sin embargo, que las medidas contestadas encajan en el ámbito de la vida privada de los demandantes.

El TEDH considera que las medidas han perseguido el fin legítimo de prevenir el desorden y la protección de los derechos y libertades de los demás. A este respecto, observa legítimo el deseo de las autoridades italianas de reafirmar la competencia exclusiva del Estado en el reconocimiento legal de las relaciones paterno-filiales — que se dan, según el derecho italiano, únicamente en caso de vínculo biológico y adopción legal— con la finalidad de proteger a los menores.

El TEDH acepta que los tribunales italianos, habiendo concluido en concreto que el nińo no sufriría un daño grave e irreparable como resultado de la separación, han llevado a cabo una ponderación adecuada entre los diferentes intereses en juego, en el marco del margen de apreciación que se les reconoce. Por ello, concluye que no ha habido una violación del artículo $8 \mathrm{CEDH}$.

\section{RESPONSABILIDAD POR DEFICIENCIAS ESTRUCTURALES DE LOS HOSPITALES PÚBLICOS}

En la sentencia recaída en el caso Aydoğdu c. Turquía, de 30 de agosto de 2016, los demandantes son los hermanos de una recién nacida que falleció a los dos días de su nacimiento debido a las carencias del servicio público de salud turco. La fallecida nació con deficiencias respiratorias. Como el hospital carecía de unidad neonatal, fue transferida a otro hospital para recibir cuidado vital de emergencia, pero debido a la falta de espacio disponible, falleció a los dos días, como se ha indicado. 
El TEDH observa en concreto que el bebé fue víctima de una falta de coordinación entre los profesionales de salud, a lo que se suman las deficiencias estructurales del sistema hospitalario de İzmir y que se le ha denegado el acceso a un tratamiento de emergencia apropiado, en violación de su derecho a la protección de su vida.

El TEDH también observa que el procedimiento penal ha carecido del requisito de eficacia y que la respuesta del sistema judicial turco a la muerte del bebé no ha reunido las garantías inherentes al derecho a la vida, observando que debido a opiniones inadecuadas de los expertos, las autoridades no han proporcionado una respuesta coherente y científicamente fundada a los problemas de establecimiento de cualquier responsabilidad.

El TEDH concluye por unanimidad que ha habido una violación del artículo $2 \mathrm{CEDH}$.

Como se trata de una situación que no es nueva ${ }^{5}$, en base al art. 46 (fuerza vinculante y ejecución de las sentencias) el TEDH llama al Estado a tomar medidas para requerir investigaciones disciplinarias y administrativas independientes e imparciales en su sistema legal, ofreciendo a las víctimas una oportunidad efectiva de participación, para asegurar que los órganos y especialistas que puedan ser llamados a ofrecer opiniones de expertos estén cualificados y tengan plena competencia para las particularidades de cada caso, y para requerir a los expertos forenses médicos a ofrecer razones adecuadas en apoyo de sus opiniones científicas.

5 Véase, al respecto, la sentencia recaída en el caso Asiye Gençc. Turquía, de 27 de enero de 2015, que comenté en Omar Bouazza Ariño (2015), «La salud en la reciente jurisprudencia del Tribunal Europeo de Derechos Humanos», Derecho y Salud, 25-2, pág. 139. 
